\title{
Significance of abnormalities in developmental trajectory and asymmetry of cortical serotonin synthesis in autism
}

\author{
Sreenivasa R. Chandana ${ }^{\mathrm{a}}$, Michael E. Behen ${ }^{\mathrm{b}}$, Csaba Juhász ${ }^{\mathrm{b}, \mathrm{d}}$, Otto Muzik ${ }^{\mathrm{b}, \mathrm{c}}$, \\ Robert D. Rothermel ${ }^{\mathrm{d}}$, Thomas J. Mangner ${ }^{\mathrm{c}}$, Pulak K. Chakraborty ${ }^{\mathrm{c}}$, \\ Harry T. Chugani ${ }^{\mathrm{b}, \mathrm{c}, \mathrm{e}}$, Diane C. Chugani ${ }^{\mathrm{a}, \mathrm{b}, \mathrm{c}, *}$ \\ ${ }^{a}$ Department of Pharmacology, Wayne State University School of Medicine, 3901 Beaubian Blvd., Detroit, MI 48201, USA \\ ${ }^{\mathrm{b}}$ Carman and Ann Adams Department of Pediatrics, Children's Hospital of Michigan, \\ Wayne State University School of Medicine, Detroit, MI 48201, USA \\ ${ }^{\mathrm{c}}$ Radiology, Children's Hospital of Michigan, Wayne State University School of Medicine, Detroit, MI 48201, USA \\ ${ }^{\mathrm{d}}$ Psychiatry and Psychology, Children's Hospital of Michigan, Wayne State University School of Medicine, Detroit, MI 48201, USA \\ ${ }^{\mathrm{e}}$ Neurology, Children's Hospital of Michigan, Wayne State University School of Medicine, Detroit, MI 48201, USA
}

Received 9 April 2004; received in revised form 4 August 2004; accepted 5 August 2004

\begin{abstract}
The role of serotonin in prenatal and postnatal brain development is well documented in the animal literature. In earlier studies using positron emission tomography (PET) with the tracer alpha $\left[{ }^{11} \mathrm{C}\right]$ methyl-L-tryptophan (AMT), we reported global and focal abnormalities of serotonin synthesis in children with autism. In the present study, we measured brain serotonin synthesis in a large group of autistic children $(n$ = 117) with AMT PET and related these neuroimaging data to handedness and language function. Cortical AMT uptake abnormalities were objectively derived from small homotopic cortical regions using a predefined cutoff asymmetry threshold ( $>2$ S.D. of normal asymmetry). Autistic children demonstrated several patterns of abnormal cortical involvement, including right cortical, left cortical, and absence of abnormal asymmetry. Global brain values for serotonin synthesis capacity (unidirectional uptake rate constant, K-complex) values were plotted as a function of age. K-complex values of autistic children with asymmetry or no asymmetry in cortical AMT uptake followed different developmental patterns, compared to that of a control group of non-autistic children. The autism groups, defined by presence or absence and side of cortical asymmetry, differed on a measure of language as well as handedness. Autistic children with left cortical AMT decreases showed a higher prevalence of severe language impairment, whereas those with right cortical decreases showed a higher prevalence of left and mixed handedness. Global as well as focal abnormally asymmetric development in the serotonergic system could lead to miswiring of the neural circuits specifying hemispheric specialization.
\end{abstract}

(C) 2004 ISDN. Published by Elsevier Ltd. All rights reserved.

Keywords: Autism; Serotonin; Alpha $\left[{ }^{11}\right.$ C $]$ methyl-L-tryptophan; PET; Cortical asymmetry; Cortical development; Language; Handedness

Abbreviations: PET, positron emission tomography; AMT, alpha $\left[{ }^{11} \mathrm{C}\right]-$ methyl-L-tryptophan; MAO-A, monoamine oxidase-A; IQ, intelligence quotient; ADI-R, Autism Diagnostic Interview-Revised; GARS, Gilliam Autism Rating Scales; CARS, Childhood Autism Rating Scales; VABS, Vineland Adaptive Behavior Scales; DSM-IV, Diagnostic and Statistical Manual of Mental Disorders-Fourth Edition; LV, left ventrical; MRI, magnetic resonance imaging; SPGR, spoiled gradient; AI, asymmetry index

* Corresponding author. Tel.: +1 313993 3847; fax: +1 3139933845.

E-mail address: dchugani@pet.wayne.edu (D.C. Chugani).
Abnormalities of serotonergic function in autism were first recognized in 1961 when Schain and Freedman reported hyperserotonemia in autistic and mentally retarded children. This result has been replicated by several groups (Hoshino et al., 1984; Anderson et al., 1987; Cook et al., 1990), and extended with the recognition that blood serotonin is also elevated in their first degree relatives (Leventhal et al., 1990; Piven and Palmer, 1999; Cook et al., 1994; Leboyer et al., 1999). How the abnormalities of blood serotonin might be related to brain serotonin, however, has not been well 
understood. Several recent studies report association of genes that may impact serotonin metabolism in autism. One such study reports the presence of a susceptibility mutation in a promoter variant of the tryptophan 2,3 dioxygenase gene (Nabi et al., 2004). Tryptophan 2,3-dioxygenase is a ratelimiting enzyme in the metabolism of tryptophan (by the kynurenine pathway), the precursor of serotonin. A mutation that results in decreased activity of this enzyme could decrease the metabolism of tryptophan by this pathway and increase the level of whole body serotonin content. Furthermore, tryptophan 2,3-dioxygenase, as well as indoleamine 2,3-dioxygenase (which also catalyses tryptophan metabolism by the kynurenine pathway), are expressed in the placenta and have a role in the prevention of allogeneic rejection of the fetus (Munn et al., 1998; Suzuki et al., 2001). Another recent study investigated the effect of maternal genotypes for monoamine oxidase-A (MAO-A) on the susceptibility of autism in their offspring. Jones et al. (2004) reported that maternal genotypes containing specific polymorphisms at the MAO-A locus show significant negative effects on the intelligence quotient (IQ) in children with autism. These results are consistent with those of a study which found that a low activity MAO-A allele, due to an upstream variable-number tandem repeat region, is associated with both lower IQ and more severe autistic behavior in children, as compared to the high-activity allele (Cohen et al., 2003). The serotonin transporter is highly expressed in the brush border membrane of the human placenta and may mediate transport of serotonin from the maternal circulation to the developing fetus (Balkovetz et al., 1989). Efforts to relate increased blood serotonin to polymorphisms of the serotonin transporter have been largely unsuccessful, although a small effect on blood serotonin has not been ruled out (Persico et al., 2000; Anderson et al., 2002; Persico et al., 2002; Betancur et al., 2002). Given that there is expression of the serotonin transporter in the placenta, a maternal modifier effect of the serotonin transporter might be a risk factor for autism.

In order to determine whether there are serotonergic abnormalities in brain in children with autism, we have evaluated serotonin synthesis capacity in vivo with positron emission tomography (PET), using the tryptophan analogue alpha $\left[{ }^{11} \mathrm{C}\right]$ methyl-L-tryptophan (AMT) as the tracer. Our previous publications illustrate two fundamentally different types of serotonergic abnormality in children with autism (Chugani et al., 1997, 1999). The first is a difference in whole brain serotonin synthesis capacity in autistic children compared to age matched nonautistic children. Global brain values for serotonin synthesis capacity were obtained for 30 healthy, seizure free autistic children, 8 of their healthy nonautistic siblings, and 16 epileptic children without autism. For non-autistic children, serotonin synthesis capacity was $>200 \%$ of adult values until the age of 5 years and then declined toward adult values. In autistic children, serotonin synthesis capacity increased gradually between the ages of 2 years and 15 years to values 1.5 times the adult normal values. These data suggested that humans undergo a period of high brain serotonin synthesis capacity during early childhood, and that this developmental process is disrupted in autistic children. The second type of abnormality we have reported relates to focal abnormalities in brain serotonin synthesis. Asymmetries of AMT uptake in frontal cortex, thalamus and cerebellum were visualized in a small sample of children with autism (Chugani et al., 1997). We have been attempting to understand the significance of these findings in relation to phenotypic variations in autistic children.

A large body of literature demonstrates that serotonin is important for several aspects of prenatal and postnatal brain development that can be related to autism (for reviews see Chugani, 2002; Gaspar et al., 2003). A key study published by Rakic and coworkers (Janusonis et al., 2004) this year demonstrated that serotonergic fibers innervate Cajal Retzius cells, which are necessary for cortical column development. Furthermore, these investigators showed that treatment with the serotonin agonist 5-methoxytryptamine during fetal development led to alterations in brain reelin levels (a glycoprotein produced by Cajal Retzius cells) and abnormalities of presubicular cortical column development. This is highly significant since both abnormal levels of reelin (Fatemi et al., 2001) and abnormalities in cortical columns (Casanova et al., 2002a,b) have been demonstrated in human autism autopsy brain tissue. Casanova et al. (2002a,b) reported that there was an increased number of minicolumns combined with fewer cells per column or greater cell dispersion in autism brain samples. Alterations in minicolumn organization in autism may have a profound impact on hemispheric specialization and functions dependent on hemispheric specialization, such as language, since there are significant differences in minicolumn organization between the left and right sides of the human brain (for review see, Hutsler and Galuske, 2003). The width of minicolumns and the distance between the columns is larger on the left than on the right (Seldon, 1981a,b; 1982; Buxhoeveden et al., 2001). Seldon (1981a,b; 1982) also showed that pyramidal cells in the posterior language cortex on the left contacted fewer columnar units than on the right. In addition, there is asymmetry in the size of the pyramidal cells constituting the minicolumns, with a greater number of large pyramidal cells in the left hemisphere than in the right hemisphere (Hutsler, 2003). The result of these changes is that pyramidal cells in the left hemisphere contact fewer adjacent minicolumns. Macrocolumns, on the other hand, appear not be asymmetric in size, but the distance between the macrocolumns was reported to be $20 \%$ greater in left than on the right in Brodmann area 22 (Galuske et al., 2000).

We now present AMT PET data for a large group of children with autism. The focus of this investigation was on the extent of asymmetry in cortical serotonin synthesis in this group of children and the relationship between cortical asymmetry and two measures of hemispheric specialization, language function and handedness. 


\section{Subjects and methods}

\subsection{Subjects}

Children with autism $(N=117 ; M=88, F=29$ : age range 2.0-15.3 years, mean age of $6.5 \pm 2.7$ years) were recruited from pediatric neurology clinics at Children's Hospital of Michigan, Detroit (this sample includes 30 children previously described in Chugani et al., 1999). The diagnosis of autism was assessed using the Autism Diagnostic Interview-Revised [ADI-R, a parent report measure (Lord et al., 1994)]; Gilliam Autism Rating Scales [GARS, a parent report measure]; and Childhood Autism Rating Scales [CARS, a behavioral observation measure]). Because of difficulty in diagnosis of children with mental age less than 24 months (Lord et al., 1994), children were included in the autistic group only if they met all the following criteria: (1) Autistic by ADI-R; (2) DSM-IV (Diagnostic and Statistical Manual of Mental Disorders-Fourth Edition) criteria for autism based on unstructured interview; (3) autism quotient greater than 85 on GARS; (4) scores higher than 30 on CARS; (5) previous diagnosis by treating neurologist or psychiatrist. The control comparison group included typically developing siblings of children with autism $(N=8 ; M=6, F=2$; age range of 8.2-14.3 years; mean age of $9.2+3.4$ years $)$ and children with epilepsy $(N=$ 16: $M=9, F=7$; age range 3 months-13.4 years; mean age, $5.73 \pm 3.6$ years). Data from this control group have been previously reported (Chugani et al., 1999). Children with epilepsy were taking one or more medications, which included phenobarbital, phenytoin, carbamazepine, valproate, clorazepate, clonazepam, lorazepam, lamotrigine, gabapentin, and vigabatrin. Autistic subjects and their siblings were not taking any medication. Details regarding the subjects are presented in Table 1. All the studies were performed in compliance with the regulations of Wayne State University Human Investigation Committee, and written informed consent of parent or legal guardian was obtained. In addition, written assent of the children was obtained when appropriate.

\subsection{AMT model for measurement of serotonin synthesis capacity}

AMT, which was developed as a tracer for serotonin synthesis with PET (Diksic et al., 1991), is an analogue of tryptophan, the precursor for serotonin synthesis. Following the intravenous administration, AMT in plasma competes with tryptophan and other large neutral amino acids for transport across the blood brain barrier. Partial conversion of AMT to $\alpha$-methyl-serotonin (AM-5HT) in brain has been demonstrated in animals (Missala and Sourkes, 1988; Diksic et al., 1990; Gharib et al., 1999; Shoaf et al., 1998, 2000). [H-3] $\alpha$-methyl-serotonin synthesized in brain was localized to serotonergic neurons and nerve terminals by combined autoradiography and tryptophan hydroxylase immunocytochemistry at the electron microscopic level (Cohen et al., 1995). However, Shoaf et al. (1998, 2000) and Gharib et al. (1999) argued that AMT cannot be used to measure serotonin synthesis since only a fraction of the AMT taken up into the tissue is converted to serotonin. These two groups of investigators concluded that AMT is primarily a measure of brain uptake of tryptophan and cannot be related to serotonin synthesis because the tracee, tryptophan, is a substrate for both protein and serotonin synthesis. Subsequently, Diksik and colleagues showed that pharmacological inhibition of tryptophan hydroxylase with $p$-chlorophenylalanine decreased the undirectional uptake of AMT, whereas inhibition of protein synthesis with cyclohexamide had no effect on the trapping of AMT in brain tissue (Tohyama et al., 2002). Thus, these data support the interpretation that the unidirectional uptake constant of AMT is related to serotonin synthesis and not protein synthesis. The absolute serotonin synthesis rate, however, cannot be obtained using AMT as a tracer due to competition with other large neutral amino acids for transport at the

Table 1

Behavioral assessment of subject groups

\begin{tabular}{|c|c|c|c|c|c|c|c|c|c|c|}
\hline \multirow[t]{2}{*}{ Group } & \multirow[t]{2}{*}{ Age } & \multicolumn{2}{|c|}{ Gender } & \multicolumn{5}{|l|}{ GARS } & \multirow[t]{2}{*}{ CARS } & \multirow[t]{2}{*}{$\mathrm{OAB}$} \\
\hline & & M & $\mathrm{F}$ & SB & Com & SI & Dev & Total & & \\
\hline Autism & $6.5(2.7)$ & 88 & 29 & $9.9(2.5)$ & $14.6(4.2)$ & $9.5(2.6)$ & $9.1(2.5)$ & 105 (15.6) & $40.5(7.5)$ & $50.6(14.1)$ \\
\hline Asymmetry & $6.7(2.6)$ & 45 & 15 & $9.8(2.6)$ & $14.7(4.1)$ & $9.6(2.4)$ & $8.9(2.3)$ & 105 (14.9) & $40.7(7.5)$ & $49.7(15.1)$ \\
\hline Right $^{\mathrm{a}}$ & $6.9(2.7)$ & 22 & 7 & $9.4(2.4)$ & $14.5(3.7)$ & $9.2(2.3)$ & $8.9(2.4)$ & $103(13.1)$ & $39.2(7.2)$ & 47.9 (12.6) \\
\hline Left $^{\mathrm{a}}$ & $6.4(2.6)$ & 23 & 8 & $10.1(2.7)$ & $15.0(4.5)$ & $9.9(2.8)$ & $8.8(2.2)$ & $106(16.6)$ & $42.2(7.7)$ & $51.3(17.2)$ \\
\hline NA & $6.3(2.9)$ & 39 & 14 & $10.3(2.3)$ & $14.4(4.2)$ & $9.7(2.5)$ & $9.4(2.8)$ & $106(15.8)$ & $40.6(7.6)$ & $52.2(13.2)$ \\
\hline Epilepsy & $5.7(3.6)$ & 9 & 7 & $5.4(2.6)$ & $10.1(6.0)$ & $4.8(2.4)$ & $7.1(6.7)$ & $70(12.6)$ & ND & $63.0(21.5)$ \\
\hline Siblings & $9.2(3.4)$ & 6 & 2 & $2.5(2.2)$ & $4.0(5.3)$ & $2.3(1.7)$ & $2.1(2.6)$ & $52(12.6)$ & $19.4(4.4)$ & $114.0(11.4)^{\mathrm{b}}$ \\
\hline
\end{tabular}

Demographics and behavioral data for subject groups. GARS: Gilliam Autism Rating Scale; GARS subscales, SB: stereotyped behavior; com: communication; SI: social interaction; dev: development; total: mean autism quotient (scores: $90-110$ : average probability of autism; 111-120: above average probability of autism; 121-130: high probability of autism); CARS: Childhood Autism Rating Scale (scores: 15-29.5: not autistic; 30-36.5: mild to moderate autism; 37-60: severe autism; OAB: overall adaptive behavior composite from Vineland Adaptive Behavior Scale in age equivalents (months of age); ND: not done; NA: no asymmetry in the AMT uptake between hemispheres. All the group values are depicted as mean of the group and standard deviation (in the parenthesis).

${ }^{a}$ Right and left represents group of autistic children with right decrease and left decrease of AMT uptake ( $\left.>8 \%\right)$ compared to the contralateral hemisphere.

b Mean full-scale intelligent quotient (Wechsler Intelligence Scale for Children, third edition). 
blood brain barrier and the presence of a large unmetabolized pool of AMT (Shoaf et al., 1998, 2000; Gharib et al., 1999; Chugani et al., 1998; Chugani and Muzik, 2000). Despite this limitation, the unidirectional uptake rate constant (K-complex) values have been found to be stable within an individual (Shoaf et al., 1998), and the rank order of regional brain values for K-complex are consistent with the rank order for serotonin content in human brain (Chugani et al., 1998). Furthermore, changes in K-complex with age, gender and pharmacological interventions are consistent with previously reported biochemical measurements of serotonin in brain tissue (for reviews see Chugani and Muzik, 2000; Diksic and Young, 2001). We have, therefore, asserted that the K-complex is an index of serotonin synthesis, which we have termed the "serotonin synthesis capacity" (Chugani et al., 1998).

In addition to metabolism by protein and serotonin synthesis, tryptophan is metabolized by tryptophan 2,3dioxygenase (Haber et al., 1993) and indoleamine 2,3dioxygenase (Yamazaki et al., 1985) via the kynurenine pathway in the brain. Under normal circumstances, the metabolites of these pathways are between 100- and 1000fold lower than the concentration of tryptophan in the brain (Saito et al., 1993). In comparison, the sum of the concentrations of serotonin and its metabolite 5-HIAA is approximately one-fifth the concentration of tryptophan in brain (Hery et al., 1977). Therefore, the kynurenine pathways are not expected to contribute to the accumulation of AMT in brain under normal circumstances. However, following ischemic brain injury or immune activation, induction of indoleamine2,3-dioxygenase can result in a 10fold increase in quinolinic acid (a metabolite of the kynurenine pathway) in brain (Saito et al., 1993), and therefore, this pathway should be considered in the disease state. We have preliminary data that AMT is a tracer of the pathway in patients with tuberous sclerosis complex and epilepsy (Chugani et al., 1998b; Chugani and Muzik, 2000). Thus, when increased uptake of AMT is observed, the kynurenine pathway must be considered.

\subsection{PET scanning procedures}

AMT was produced as described by Chakraborty et al. $(1995,1996)$. Subjects were fasted for $6 \mathrm{~h}$ in order to obtain stable plasma tryptophan and large neutral amino acid levels (Stout et al., 1998) during the study. Two venous lines were established: one for tracer injection and one for collection of timed blood samples $(0.5 \mathrm{ml} / \mathrm{sample}$, collected at $0,20,30,40,50$ and 60 min following tracer injection). Radioactivity in plasma was measured using a Cobra II gamma well counter (Packard Instruments, Meriden, CT), and tryptophan concentration was measured by HPLC as previously described (Wolf and Kuhn, 1986). Tryptophan values did not change over the time course of the study and did not differ among groups. Heart rate, blood pressure, pulse oximetry, and blood gases also were measured during the study, and the scalp EEG was monitored continuously in epileptic children. All PET studies reported here were interictal studies. Children were sedated with either nembutal $(5 \mathrm{mg} / \mathrm{kg}$ i.v.) or midazolam $(0.2-0.4 \mathrm{mg} / \mathrm{kg}$ i.v.) if necessary. Prior studies performed in our laboratory on five adults each scanned twice (once without and once with sedation using midazolam) have found no significant difference in serotonin synthesis between the two testing conditions (Chugani et al., unpublished data).

PET studies were performed using the Siemens EXACT/ HR whole body positron tomograph (Knoxville, TN). The PET scan sequence began with a 15 min transmission scan of the chest. Following completion of the transmission scan, AMT $(0.1 \mathrm{mCi} / \mathrm{kg})$ was injected as a slow bolus over $2 \mathrm{~min}$. Beginning at the time of injection, a 20 min dynamic PET scan of the heart was performed (dynamic sequence: $12 \times$ $10 \mathrm{~s}, 3 \times 60 \mathrm{~s}, 3 \times 300 \mathrm{~s})$ in order to obtain the left ventricular (LV) input function. Beginning at $25 \mathrm{~min}$ following tracer injection, seven $5 \mathrm{~min}$ scans of the brain were performed using 3D acquisition mode. The brain emission scan was followed by a 15 min transmission scan of the head. Measured attenuation correction and decay correction was applied to all images.

In order to obtain the arterial input function for the whole duration of the study, the LV region time-activity curve was combined with venous blood sample values for AMT drawn at 20, 30, 40, 50 and 60 min post-injection. At these late times, arterial blood and venous blood are in approximate equilibrium. The LV input function was derived as previously described from a left ventricular region-of-interest (Muzik et al., 1994; Suhonen-Polvi et al., 1995). The so obtained arterial input function was then used together with the dynamic brain image sequence to calculate parametric images of the K-complex by applying the Patlak-plot approach using data from 25 to $60 \mathrm{~min}$ post-injection (Muzik et al., 1997; Chugani et al., 1998). The graphical approach was described by Patlak et al. (1983) for the determination of the undirectional uptake rate constant $\mathrm{K}$, which represents the uptake of AMT from the plasma to brain tissue followed by physiological trapping in an irreversible compartment. This approach assumes that the system to be analyzed consists of a homogenous tissue region with any number of compartments that communicate reversibly with the blood. In addition, there must be at least one compartment that the tracer enters in an irreversible manner. The units of the $\mathrm{K}$-complex are $\mathrm{ml} / \mathrm{g} / \mathrm{min}$. Brain regions of interest were drawn manually on images representing the $\mathrm{K}$ complex on all supratentorial planes beginning from the plane containing the centrum semiovale. The average value of the K-complex was determined for the whole brain as well as for the left and right hemispheres. Finally, AMT uptake images were generated by summing brain image frames between 30 and $55 \mathrm{~min}$ following tracer injection. 


\subsection{MRI scanning procedures}

MRI (magnetic resonance imaging) studies were performed on a GE 1.5 Tesla Signa unit (GE Medical Systems, Milwaukee, Wisconsin). Volumetric imaging in this study was performed utilizing a spoiled gradient echo (SPGR) sequence. The 3D SPGR technique generated 124 contiguous $1.5 \mathrm{~mm}$ sections of the entire head using a 35/ 5 (TR/TE) pulse sequence, flip angle of $35^{\circ}$, matrix size of $256 \times 128$, and FOV of $240 \mathrm{~mm}$. These images were performed in the coronal plane, and the imaging time for this sequence was $9.5 \mathrm{~min}$. Sedation was employed when necessary as described above. Coregistration of AMT PET and MRI image volumes was performed using a multipurpose three-dimensional registration technique (MPITool) (Pietrzyk et al., 1990, 1994).

\subsection{Determination of cortical PET abnormalities}

The extent of regional cortical abnormalities in AMT PET uptake images was identified using an objective method based on a semi-automated software package applied to all supratentorial planes of the PET studies (Muzik et al., 1998, 2000). This procedure allows the definition of abnormal cortical areas based on asymmetry measures derived from homotopic cortical areas according to a predefined cutoff threshold (see Fig. 1A). In order to establish a cutoff threshold for abnormal asymmetry, we measured the mean asymmetries (AI) of AMT tracer uptake in the sibling control subjects. These values ranged between 3.1 and $5.2 \%$, and the mean $\mathrm{AI} \%+2$ S.D. ranged between 4.1 and $7.6 \%$. Therefore, an $8 \%$ asymmetry threshold was used to identify cortical regions with abnormally low AMT uptake in the autistic children. Those cortical areas, which exceeded the $8 \%$ asymmetry threshold, were 'marked' on the side showing the decrease. A 'marked file' containing the cortical regions with abnormalities was created for each AMT PET study and further processed using the 3D-Tool software package (Von Stockhausen et al., 1998). This software combines methods for segmentation, visualization and quantitative analysis of coregistered multimodality volume data. The brain was automatically segmented from MRI data and surface views were created. Functional data obtained from the 'marked' AMT PET uptake image volumes were projected onto the MRI brain surface using a reverse gradient fusion (Stokking et al., 1994)(Fig. 1B-D).

\subsection{Language and handedness assessments}

The Vineland Adaptive Behavior Scale (VABS, Sparrow et al., 1984) was utilized to assess language in autistic children. This measure has been shown to be particularly useful in evaluating such functions in children with pervasive developmental disorders who often are unable to complete formal language evaluations (Perry and Factor, 1989). Because many autistic children have severely
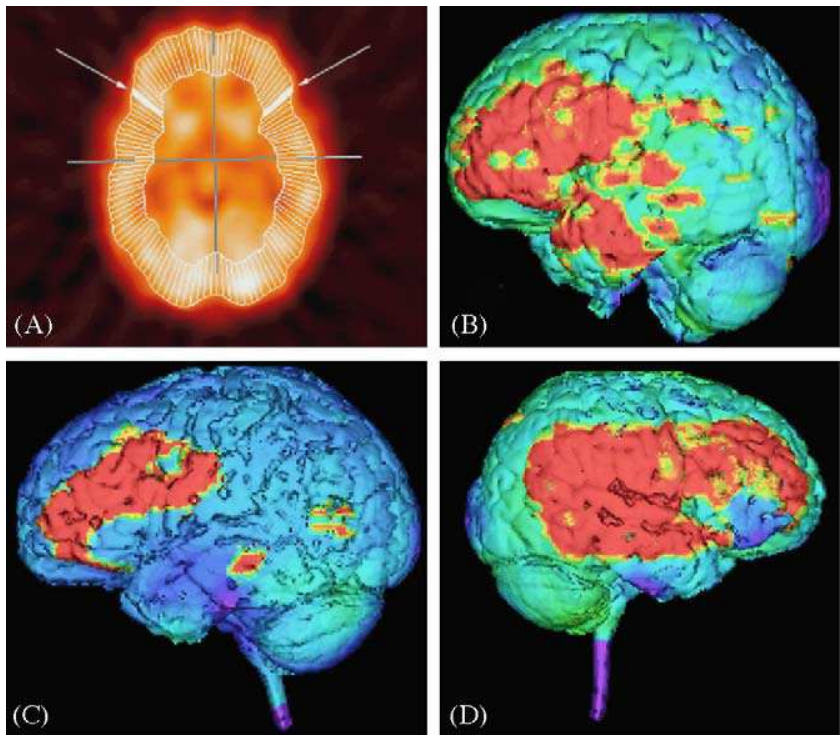

Fig. 1. Patterns of cortical serotonergic abnormalities in autism. (1A) This figure shows the method for objective assessment of AMT concentration asymmetry in the PET image. Regional cortical AMT uptake asymmetries were identified and marked using an objective method based on a semiautomated software package applied to all supratentorial planes of the AMT uptake image volumes. The arrows show two small homotopic regions on either side, whose tracer concentration values are compared in order to determine cortical asymmetry. Regions exceeding a predefined threshold were marked in red. Co-registered MRI image volumes were skull-stripped, surface rendered and anatomical and functional data was merged using the inverse gradient fusion method. This approach allows a full three-dimensional assessment of the location and extent of cortical abnormalities. Cortical decreases of AMT uptake (red areas) in three autistic children in (1B) the frontal cortex (left hemisphere), (1C) frontal and temporal cortices (left hemisphere), and (1D) frontal, parietal and temporal cortices (right hemisphere) are shown.

impaired or absent expressive language, and since a large portion of our sample had not yet developed expressive language function, when examining associations between language functions and imaging data we included only children 5 years and above $(n=76)$. Since our autistic sampled included low functioning children, we divided them into several groups based on VABS Communication (VABSCOM) scores. These groups include children with severe language impairment (VABS-COM score <35), moderate language impairment (VABS-COM score between 35 and 50 ) and mild language impairment (VABS-Com score $>50$ ). We then further divided the moderate language impairment group based on the presence or absence of phrase speech. Children, who had not yet developed phrase speech or their first phrase after 6 years of age, were placed into the severe language impairment group. Children with phrase speech or the age of onset of their first phrase below 6 years of age, were included in the mild language impairment group. For handedness assessment, parents were asked to indicate the hand preference of their child for several common daily activities (for example, eating, playing, drawing). Based on this parental report, subjects $(n=113)$ were classified as right-handed, left-handed or mixed-handed. 


\subsection{Statistical analyses}

In order to determine whether there are significant differences among patient groups with regard to global brain serotonin synthesis capacity with age, we applied a multiple regression analysis. The multiple regression analysis was performed hierarchically by first entering the age followed by the group and finally the (group $\times$ age) interaction, both coded as dummy variables. A similar multiple regression analysis was performed to determine whether serotonin synthesis capacity values differ between the two hemispheres in three groups of children: children with left cortical decreases of AMT uptake, children with right cortical decreases and children who did not show asymmetry of AMT uptake. Finally, we followed up the multiple regression analysis with a simple paired $t$-test between hemispheres applied separately for each group. A chi-square analysis was performed to evaluate differences in language and handedness between groups of autistic children defined by the presence or absence and side of cortical asymmetry (left decrease versus right decrease versus no asymmetry).

\section{Results}

\subsection{Cortical asymmetry assessment}

Using the objective measure of cortical asymmetry, 55\% (64/117) of the children with autism showed abnormal cortical asymmetry. Among the autistic children whose AMT PET scans showed abnormal asymmetry, left sided decreases of AMT uptake were seen in 31 subjects, right sided decreases in 29 and bilateral decreases (nonhomotopic cortical regions) in 4 children. Cortical AMT uptake decreases were detected in frontal cortex in 90\% (58/ 64) of asymmetric cases, and included temporal lobe in $47 \%$ (30/64) and parietal lobe in 30\% (19/64) of cases. Representative 3D reconstructed MR image volumes with 'marked' regions of abnormal cortical asymmetry are shown in Fig. 1B-D. Cortical regions showing asymmetry included inferior prefrontal cortex (BA44, 45, 47), inferior parietal lobule (BA40), superior temporal gyrus (BA22, 21), and inferior occipital gyrus (BA18, 19).

\subsection{Developmental trajectory of serotonin synthesis capacity}

Change in whole brain serotonin synthesis capacity (Kcomplex) with age was assessed in autistic children grouped by asymmetry versus no asymmetry for comparison with the non-autistic control group (the 4 children with bilateral nonhomotopic AMT uptake decreases were excluded in this analysis). The results of linear fit for the whole-brain and hemispheric serotonin synthesis capacity as a function of the age for each group are shown in Fig. 2. Application of the full multiple regression model revealed a significant (group

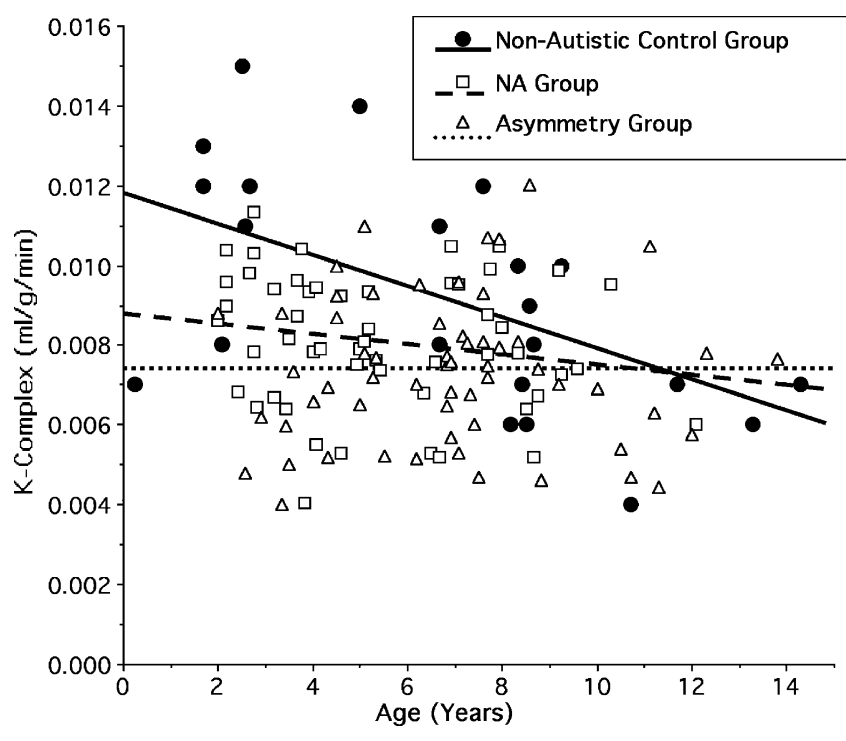

Fig. 2. Changes in the whole brain serotonin synthesis capacity (K-complex) with age in autistic children. Whole brain K-complex values are plotted as a function of age for the non-autistic control group $(n=24$; closed circles) and the group of autistic children with (asymmetry group; $n=60$; open triangles) and without abnormal asymmetries between hemispheres (no asymmetry group; $n=53$; open squares).

$\times$ age) interaction as well as a significant group effect. The non-autistic control group differed significantly from the asymmetry and no asymmetry groups in both the intercept $(P=0.001)$ and slope $(P=0.009)$ parameters. Furthermore, no significant differences were determined between the two autistic groups $(P=0.258$ for intercept and $P=0.581$ for slope). The non-autistic control group showed a significant negative slope of the linear plot $(P=0.001)$. In contrast, the slope parameters derived from both the no asymmetry and asymmetry groups were not significantly different from zero ( $P=0.20$ and 0.85 , respectively).

In order to determine whether cortical asymmetries represent decreases on the side with lower AMT uptake or increases on the side with higher AMT uptake, hemispheric values for K-complex for the three groups of autistic children were compared. Visual inspection of linear fits depicting the relationship between hemispheric serotonin synthesis capacity values (K-complex) with age in a group of children with lower cortical AMT uptake on the left, lower cortical AMT uptake on the right and a group of children with no cortical asymmetries, indicated that both hemispheres of the no asymmetry group are higher than both hemispheres of the two asymmetry groups (Fig. 3). Comparison of left hemispheric serotonin synthesis capacity values among the three groups using a multiple regression analysis showed a significant difference in the intercept between the no asymmetry group and the group showing lower AMT uptake in cortex on the left $(P=0.005)$ but not with the group showing lower cortical uptake on the right $(P$ $=0.426$ ). In contrast, no significant differences were observed when performing a similar comparison with respect to right hemispheric serotonin synthesis capacity 


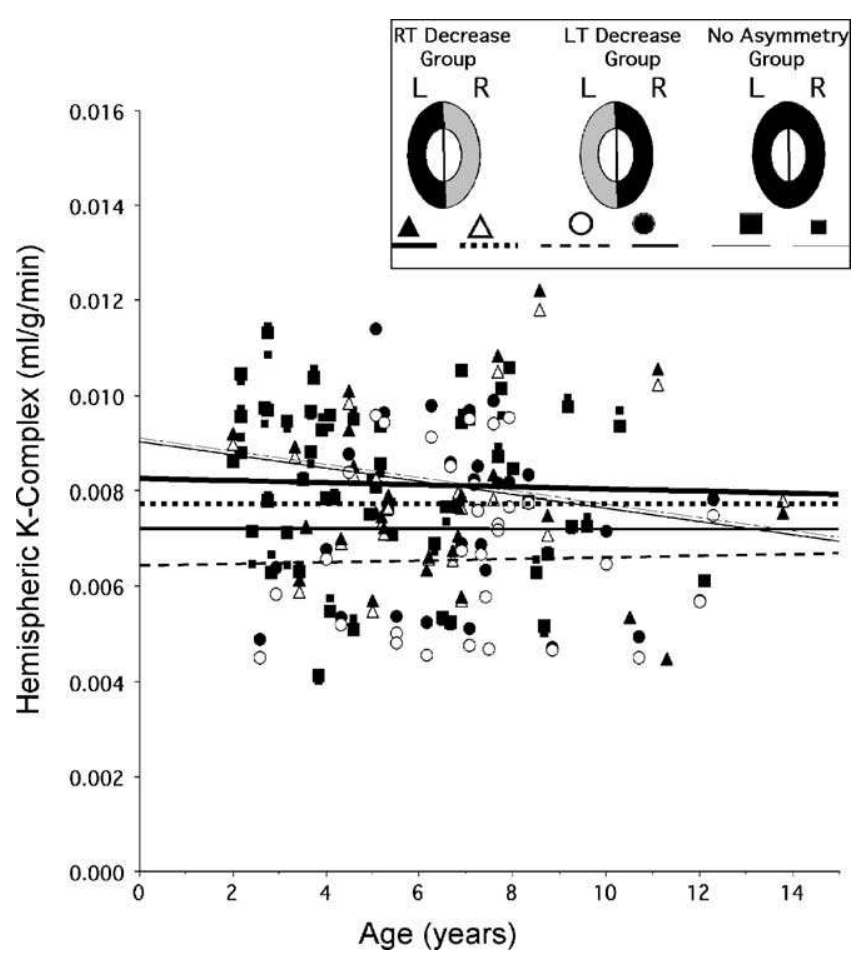

Fig. 3. Hemispheric serotonin synthesis capacity (K-complex) as a function of age in autistic children. Right and left hemispheric K-complex values are plotted as a function of age for groups of autistic children divided in three groups based upon pattern of cortical asymmetry: AMT uptake lower on right side ( $n=29$; right hemisphere: open triangles, left hemisphere: closed triangles), AMT uptake lower on left side ( $n=31$; left hemisphere: open circles, right hemisphere: closed circles) or no asymmetry $(n=53$, left hemisphere: large squares, right hemisphere: small squares). Linear fits depicting the relationship between hemispheric serotonin synthesis capacity values (K-complex) with age show that both hemispheres of the no asymmetry group are higher than both hemispheres of the two asymmetry groups, suggesting that the asymmetries in cortical uptake are due to ipsilateral decreases rather than increases in the contralateral hemisphere.

values in the three groups due to the smaller difference between hemispheric values in the right decrease group (Fig. 3). Finally, applying a paired $t$-test, significant differences in serotonin synthesis capacity values were found between the left and right hemisphere of each individual patient in the left decrease group (paired $t=6.25, P=0.001$ ) as well in the right decrease group (paired $t=2.48, P=$ 0.019 ), but not in the no asymmetry group (paired $t=0.67, P$ $=0.51$ ). Based upon these results, we conclude that the asymmetries in cortical uptake are due to ipsilateral decreases rather than to increases in the contralateral hemisphere.

\subsection{Relationship of cortical asymmetry to language function and handedness}

In order to determine whether asymmetry of cortical serotonin synthesis was associated with language, we explored the incidence of functional language impairment in this sample by dividing all subjects over the age of 5 years into three cortical asymmetry groups: a no asymmetry $(n=$

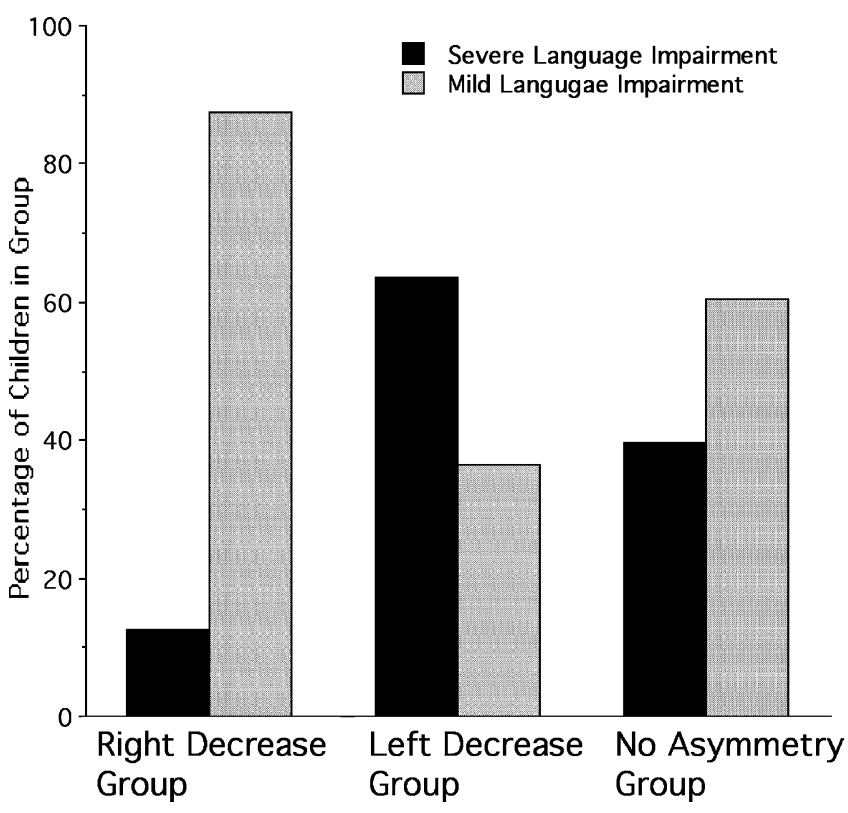

Fig. 4. Language abnormalities in autistic children with and without abnormal asymmetries in AMT uptake. The plot shows the percentage of autistic children over 5 years of age with mild and severe language impairment in the groups with right decrease $(n=16)$, left decrease $(n=22)$ and no asymmetry ( $n=38$, NA group) in AMT uptake. Degree of language impairment was determined based on Vineland Adaptive Behavior ScaleCommunication Domain and presence or absence of phrase speech. Chisquare analysis showed significantly higher incidence of severe language impairment in the left decrease group compared to the right decrease group $(P=0.002)$.

38), a left decrease $(n=22)$ and a right decrease $(n=16)$ group. An overall group comparison using a chi-square analysis, revealed a significant group difference in language impairment among the groups $\left[\chi^{2}(2)=10.1, P=0.006\right]$. Autistic children with left hemispheric decreases showed a higher incidence of severe language impairment (Fig. 4). The left decrease group showed a significant group difference in comparison with the right decrease group $\left[\chi^{2}(1)=9.93, P=0.002\right]$, while there was no statistical significance in the frequency of language of abnormalities between the left decrease and non-asymmetric groups $\left[\chi^{2}\right.$ (1) $=4.2, P=0.12]$. With regard to handedness, the entire sample of autistic children $(n=113$, four children with bilateral asymmetries were excluded) was dividing into three cortical asymmetry groups: a non-asymmetric $(n=53)$, a left decrease $(n=31)$ and a right decrease $(n=29)$ group (Fig. 5). An overall chi-square analysis revealed no statistically significant group difference in handedness $\left[\chi^{2}\right.$ (4) $=7.2, P=0.12]$. However, an independent chi-square analysis, comparing the right decrease versus left decrease groups, revealed a trend $\left[\chi^{2}(2)=4.88, P=0.087\right]$ in the direction of the right decrease group having increased incidence of left and mixed handedness. There was also a trend for the right decrease group having an increase in left and mixed handedness compared to the no asymmetry group $\left[\chi^{2}(2)=5.7, P=0.057\right]$. 


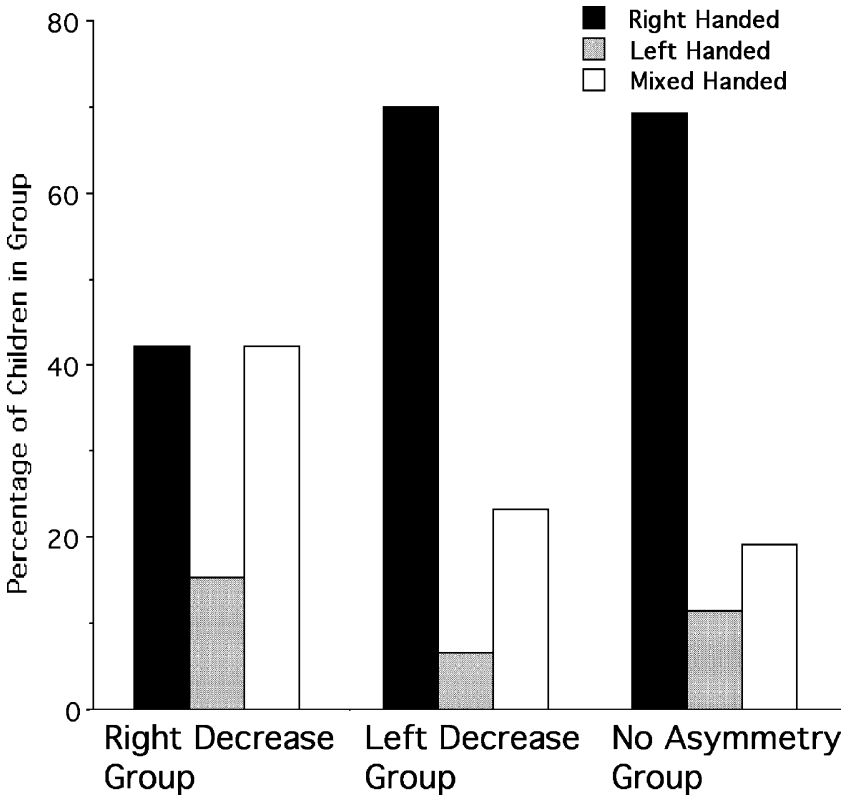

Fig. 5. Handedness in autistic children with and without abnormal asymmetry in AMT uptake. Children with autism were grouped based on right ( $n$ $=29)$ and left $(n=31)$ hemispheric decreases of AMT uptake and no asymmetry $(n=53)$. The plot shows the percentage of autistic children with right, left and mixed handedness in each group. Chi-square analysis showed trends for more left and mixed handedness in the right decrease group compared to the left decrease group $(P=0.087)$ and the no asymmetry group $(P=0.057)$.

\section{Discussion}

The data presented here and in our previous publications illustrate two fundamentally different types of serotonergic abnormality in children with autism (Chugani et al., 1997, 1999). The first is a difference in the change with age in whole brain serotonin synthesis capacity compared to age matched nonautistic children. This global abnormality of serotonin synthesis may be related to altered cortical minicolumn organization shown in autism autopsy brain tissue (Casanova et al., 2002a,b), as suggested by Janusonis et al. (2004). The second type of abnormality involves cortical asymmetries of serotonin synthesis affecting either the left or right cortex and affects variable territories including frontal, temporal, parietal cortices and occipital cortices. The present study demonstrates several patterns of cortical serotonergic abnormalities in autistic children, extending our previous report of decreased serotonin synthesis in frontal cortex (Chugani et al., 1997). While $90 \%$ of those children with cortical asymmetry showed involvement of the frontal lobe, decreased AMT uptake extended to the temporal lobe in one-half of the subjects and included the parietal lobe in one-third. The relatively decreased cortical serotonin synthesis in cortex was lower on the left in just over one half of the subjects. Differences in language function and handedness, which indicate hemispheric specialization, were found among the groups. Autistic children with decreased left cortical serotonin synthesis showed an increased incidence of severe language impairment compared to those with right side abnormalities and those without cortical asymmetry. Additionally, there was a trend for higher incidence of left and mixed handedness in the children with right cortical decreases in serotonin synthesis. These data suggest that the different patterns of cortical abnormality in serotonin synthesis are related to dysfunction in hemispheric specialization in these autistic children.

We suggest three possible explanations for the asymmetries of cortical serotonin synthesis observed in our sample. The first explanation is that at some point in early development, cortical asymmetry of serotonin synthesis is normal and is part of the mechanism responsible for asymmetry of the cortical microcircuitry: the increased size and spacing of minicolumns on the left (Seldon, 1981a,b; 1982; Buxhoeveden et al., 2001), the increased size of pyramidal cells on the left (Hutsler, 2003), the increased neuropil of the left and the increased spacing between the functional macrocolumn units (Galuske et al., 2000). The presence of abnormal cortical asymmetry in serotonin synthesis observed in approximately one-half of the autistic children might then represent another manifestation of the abnormality in the developmental regulation of serotonin synthesis. Secondly, we propose that early damage to the dominant left hemisphere leads to compensatory changes in the right hemisphere to support language based on the recognition that damage to the dominant left hemisphere leads to compensatory changes to the right hemisphere to support language (Rasmussen and Milner, 1977; Muller et al., 1999; Curtiss and de Bode, 2003). Thus, we propose that the presence of smaller, more closely spaced minicolumns is a type of 'damage' requiring compensatory changes. This function might be shifted to the right as would happen with stroke, trauma, malformation, or hemispherectomy, in which the right hemisphere is a relatively suitable substrate for reorganization. Interestingly, Mayberg et al. (1988) showed that 5-HT2 receptor binding was higher in patients with right hemisphere stroke compared to those with left sided stroke, and suggested an asymmetry in the biochemical response of the serotonergic system after injury. Evidence for a compensatory change to facilitate language function on the right in autism comes from a study using structural imaging by Herbert et al. (2002), which showed abnormal structural asymmetry in language association cortex in autistic boys. They reported that language-related inferior frontal cortex was $27 \%$ larger on the right in the autistic group compared to $17 \%$ larger on the left in control subjects. On the other hand, if minicolumn spacing is affected to the same extent in both hemispheres (Casanova et al., 2002 reported a significant effect of hemisphere, but did not further describe the differences), reorganization might be more likely to involve the left hemisphere, and the compensatory changes in microcircuit organization on the left side might be attempted through modifications of pyramidal cell size and regulation of dendrite length, 
branching and spine density (Yan et al., 1997). Finally, the asymmetries in cortical serotonin synthesis shown in our data may also be related to the innervation of cortical macrocolumns by thalamocortical afferent projections. The serotonin transporter is transiently expressed by glutamatergic thalamocortical afferents (D'Amato et al., 1987; Bennett-Clark et al., 1996; Lebrand et al., 1996) during the first 2 postnatal weeks in rodents. Postnatal serotonin levels regulate the size of cortical barrel macrocolumns: too little serotonin leads to smaller barrel macrocolumns and too much serotonin leads to larger barrels. Depletion of serotonin during the postnatal period delays the development of the barrel fields of the rat somatosensory cortex (Blue et al., 1991; Osterheld-Haas et al., 1994) and decreases the size of the barrel fields (Bennett-Clarke et al., 1994). In contrast, increased serotonin brain levels during this critical period, as in the MAO-A knock-out mouse or serotonin transporter knockout mouse (Cases et al., 1995; Salichon et al., 2001; Persico et al., 2003), results in increased tangential arborization of these axons resulting in blurring of the boundaries of the cortical barrels (Cases et al., 1996). If lower serotonin in cortex leads to smaller cortical barrels, lower serotonin would lead to innervaton of fewer minicolumns per barrel in normal cortex. In cortex with smaller, more tightly packed columns as reported in autism, decreased serotonin might normalize the number of minicolumns per macrocolumn defined by thalamocortical innervation. It must be noted, however, that the microcircuitry asymmetries have been measured in discrete temporal cortical regions and, therefore, these microscopic cortical asymmetries may not be found throughout the cortical regions showing asymmetries in serotonin synthesis measured with AMT PET.

How might global and focal changes in brain serotonin synthesis be related to hyperserotonemia? An answer to this question may be attempted by considering the rat "hyperserotonemic model of autism" proposed by Whitaker-Azmitia and co-workers (Whitaker-Azmitia, 2001; Kahne et al., 2002). These investigators administered the serotonin agonist 5-methoxytryptamine between prenatal day 12 and postnatal day 20 (postnatal day 20 is the approximate age of weaning in the rat). In this model, rat pups showed altered behavior and loss of serotonergic terminals throughout the cortex. While loss of cortical serotonergic fibers is consistent with our human data showing cortical decreases in AMT uptake, this model, which includes postnatal treatment with a serotonin agonist, seems inconsistent with our data showing lower serotonin synthesis in young autistic children. However, the youngest autistic child we have studied was 2 years old. In the rat model, the serotonin agonist is discontinued before the equivalent age of a 2 year-old human in the rat. Although we have focused the interpretation of our human data on a lack of developmental regulation of serotonin synthesis, it is also possible that there is a shift in the developmental curve, such that serotonin synthesis levels may have already decreased

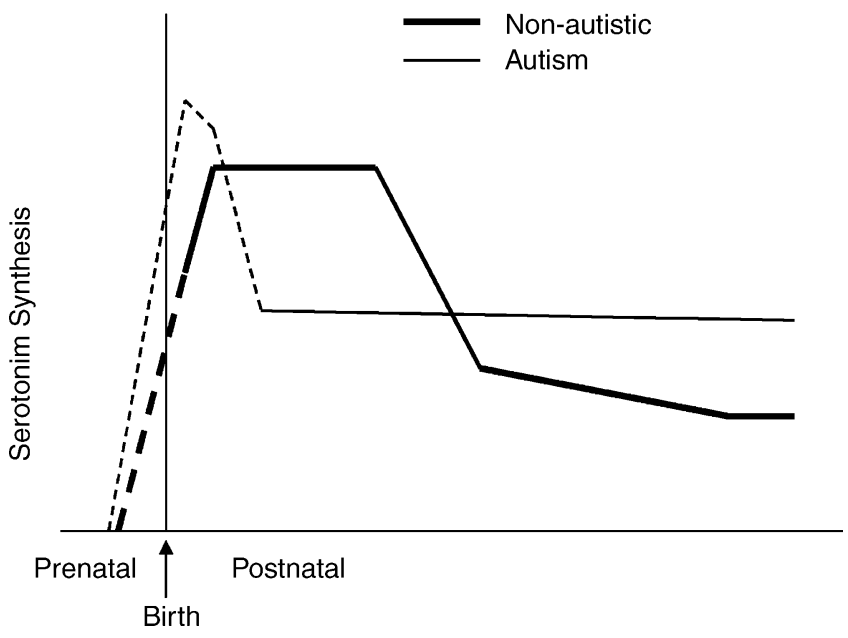

Fig. 6. A hypothetical model for deviation from the normal developmental trajectory of serotonin synthesis in autism. The solid lines represent the existing data for autistic (thinner line) and non-autistic (thicker line) children from our human studies. The interrupted lines indicate the potential serotonin synthesis changes in the prenatal and immediate postnatal period in autistic and non-autistic children, suggested based upon the animal model of hyperserotonemia. Elevated prenatal brain serotonin in autistic children might also be related to altered maternal serotonin and/or tryptophan transfer to the fetus.

by age 2 years (Fig. 6). Indeed, such a shift to the left in the brain growth curve of autistic children has been reported by Courchesne and coworkers. They reported abnormal acceleration of brain growth in the first 2 years of life, followed by slower than normal brain growth thereafter (Courchesne et al., 2001; Carper et al., 2002; Courchesne et al., 2003). Finally, high serotonin levels might occur in the fetus due to genetic factors in the mother or the fetus, since serotonin is transported across the placenta via serotonin transporters (Balkovetz et al., 1989).

\section{Acknowledgements}

This study was supported by NIH grant R01 HD34942, the Mental Illness Research Association (MIRA) and the Pheasant Ring Foundation. We wish to thank the children and their families who participated in this study. We would like to express our gratitude to Galina Rabkin, CNMT, Teresa Jones, CNMT, Angela Wigeluk, CNMT, Mei-li Lee, M.S., Giselle Baillargeon, RN, Anna Deboard, RN, and Kris Baird, B.S. for their expert technical assistance in performing the PET studies.

\section{References}

Anderson, G.M., Freedman, D.X., Cohen, D.J., Volkmar, F.R., Hoder, E.L., McPhedran, P., Minderaa, R.B., Hansen, C.R., Young, J.G., 1987. Whole blood serotonin in autistic and normal subjects. J. Child Psychol. Psychiatry 28 (6), 885-900. 
Anderson, G.M., Gutknecht, L., Cohen, D.J., Brailly-Tabard, S., Cohen, J.H., Ferrari, P., Roubertoux, P.L., Tordjman, S., 2002. Serotonin transporter promoter variants in autism: functional effects and relationship to platelet hyperserotonemia. Mol. Psychiatry 7 (8), 831-836.

Balkovetz, D.F., Tiruppathi, C., Leibach, F.H., Mahesh, V.B., Ganapathy, V., $1989 \mathrm{Feb} 5$. Evidence for an imipramine-sensitive serotonin transporter in human placental brush-border membranes. J. Biol. Chem. 264 (4), 2195-2198.

Bennett-Clarke, C.A., Leslie, M.J., Lane, R.D., Rhoades, R.W., 1994. Effect of serotonin depletion on vibrissae-related patterns in the rat's somatosensory cortex. J. Neurosci. 14, 7594-7607.

Bennett-Clark, C.A., Chiaia, N.L., Rhoades, R.W., 1996. Thalamocortical afferents in rat transiently express high-affinity serotonin uptake sites. Brain Res. 733, 301-306.

Betancur, C., Corbex, M., Spielewoy, C., Philippe, A., Laplanche, J.L., Launay, J.M., Gillberg, C., Mouren-Simeoni, M.C., Hamon, M., Giros, B., Nosten-Bertrand, M., Leboyer, M., 2002. Serotonin transporter gene polymorphisms and hyperserotonemia in autistic disorder. Mol. Psychiatry 7 (1), 67-71.

Blue, M.E., Erzurumlu, R.S., Jhaveri, S., 1991. A comparison of pattern formation by thalamocortical and serotonergic afferents in the rat barrel field cortex. Cereb. Cortex 1, 380-389.

Buxhoeveden, D.P., Switala, A.E., Litaker, M., Roy, E., Casanova, M.F., 2001. Lateralization of minicolumns in human planum temporale is absent in nonhuman primate cortex. Brain Behav. E 57, 349-358.

Carper, R.A., Moses, P., Tigue, Z.D., Courchesne, E., 2002. Cerebral lobes in autism: early hyperplasia and abnormal age effects. Neuroimage 16 (4), 1038-1051.

Casanova, M.F., Buxhoeveden, D.P., Brown, C., 2002a. Clinical and macroscopic correlates of minicolumnar pathology in autism. J. Child Neurol. 17, 692-695.

Casanova, M.F., Buxhoeveden, D.P., Switala, A.E., Roy, E., 2002b. Minicolumnar patholofy in autis. Neurology 58, 428-432.

Cases, O., Seif, I., Grimsby, J., Gaspar, P., Chen, K., Pournin, S., Müller, U., Aguet, M., Babinet, C., Shih, J.C., De Maeyer, E., 1995. Aggressive behavior and altered amounts of brain serotonin and norepinephrine in mice lacking MAOA. Science 268, 1763-1766.

Cases, O., Vitalis, T., Seif, I., De Maeyer, E., Sotelo, C., Gaspar, P., 1996. Lack of barrels in the somatosensory cortex of monoamine oxidase Adeficient mice: role of a serotonin excess during the critical period. Neuron 16, 297-307.

Chakraborty, P.K., Mangner, T.J., Chugani, D.C., Muzik, O., Chugani, H.T., 1995. A high-yield and simplified procedure for the synthesis of alpha$\left[{ }^{11}\right.$ C $]$ methyl-L-tryptophan. J. label Comp. Radiopahrm. 37, 619-621.

Chakraborty, P.K., Mangner, T.J., Chugani, D.C., Muzik, O., Chugani, H.T., 2004. A high-yield and simplified procedure for the synthesis of alpha[11C]methyl-L-tryptophan. Nucl. Med. Biol. 23 (8), 1005-1008.

Chugani, D.C., Muzik, O., Rothermel, R., Behen, M., Chakraborty, P., Mangner, T., da Silva, E.A., Chugani, H.T., 1997. Altered serotonin synthesis in the dentatothalamocortical pathway in autistic boys. Ann. Neurol. 42, 666-669.

Chugani, D.C., Muzik, O., Chakraborty, P., Mangner, T., Chugani, H.T., 1998. Human brain serotonin synthesis capacity measured in vivo with alpha-[C-11]methyl-L-tryptophan. Synapse 28 (1), 33-43.

Chugani, D.C., Heyes, M.P., Kuhn, D.M., Chugani, H.T., 1998b. Evidence that $\alpha[$ C-11]methyl-L-tryptophan PET traces tryptophan metabolism via the kynurenine pathway in tuberous sclerosis complex. Soc. Neurosci. Abstr. 24, 1757.

Chugani, D.C., Muzik, O., Behen, M., Rothermel, R., Janisse, J.J., Lee, J., Chugani, H.T., 1999. Developmental changes in brain serotonin synthesis capacity in autistic and nonautistic children. Ann. Neurol. 45, 287295.

Chugani, D.C., 2002. Role of altered brain serotonin mechanisms in autism. Mol. Psychiatry 7 (Suppl.), S16-S17.

Chugani, D.C., Muzik, O., 2000. $\alpha$ [C-11]Methyl-L-tryptophan PET maps brain serotonin synthesis and kynurenine pathway metabolism. J. Cereb. Blood Flow Metab. 20, 2-9.
Cohen, Z., Tsuiki, K., Takada, A., Beaudet, A., Diksic, M., Hamel, E., 1995. In vivo-synthesis radioactively labelled $\alpha$-methyl serotonin as a selective tracer for visualization of brain serotonin neurons. Synapse 21, $21-$ 28.

Cohen, I.L., Liu, X., Schutz, C., White, B.N., Jenkins, E.C., Brown, W.T., Holden, J.J., 2003. Association of autism severity with a monoamine oxidase A functional polymorphism. Clin. Genet. 64 (3), 190-197.

Cook Jr., E.H., Leventhal, B.L., Heller, W., Metz, J., Wainwright, M., Freedman, D.X., 1990. Autistic children and their first-degree relatives: relationships between serotonin and norepinephrine levels and intelligence. J. Neuropsychiatry Clin. Neurosci. 2 (3), 268-274.

Cook Jr., E.H., Charak, D.A., Arida, J., Spohn, J.A., Roizen, N.J., Leventhal, B.L., 1994. Depressive and obsessive-compulsive symptoms in hyperserotonemic parents of children with autistic disorder. Psychiatry Res. 52 (1), 25-33.

Courchesne, E., Carper, R., Akshoomoff, N., 2003. Evidence of brain overgrowth in the first year of life in autism. JAMA 290 (3), 337-344.

Courchesne, E., Karns, C.M., Davis, H.R., Ziccardi, R., Carper, R.A., Tigue, Z.D., Chisum, H.J., Moses, P., Pierce, K., Lord, C., Lincoln, A.J., Pizzo, S., Schreibman, L., Haas, R.H., Akshoomoff, N.A., Courchesne, R.Y., 2001. Unusual brain growth patterns in early life in patients with autistic disorder: an MRI study. Neurology 57 (2), 245-254.

Curtiss, S., de Bode, S., 2003. How normal is grammatical development in the right hemisphere following hemispherectomy? The root infinite stage and beyond. Brain Lang. 86, 193-206.

D'Amato, R.J., Blue, M.E., Largent, B.L., Lynch, D.R., Ledbetter, D.J., Molliver, M.E., Snyder, S.H., 1987. Ontogeny of the serotonergic projection to rat neocortex: transient expression of a dense innervation to primary sensory areas. Proc. Natl. Acad. Sci. 84, 4322-4326.

Diksic, M., Nagahiro, S., Sourkes, T.L., Yamamoto, Y.L., 1990. A new method to measure brain serotonin synthesis in vivo. I. Theory and basic data for a biological model. J. Cereb. Blood Flow Metab. 9, 1-12.

Diksic, M., Nagahiro, S., Chaly, T., Sourkes, T.L., Yamamoto, Y.L., Feindel, W., 1991. Serotonin synthesis rate measured in living dog brain by positron emission tomography. J. Neurochem. 56, 153-162.

Diksic, M., Young, S.N., 2001. Study of the brain serotonergic system with labeled $\alpha$-methyl-L-tryptophan. J. Neurochem. 78, 1-17.

Fatemi, S.H., Stary, J.M., Halt, A.R., Realmuto, G.R., 2001. Dysregulation of Reelin and Bcl-2 proteins in autistic cerebellum. J. Autism Dev. Disorders 31 (6), 529-535.

Gaspar, P., Cases, O., Maroteaux, L., 2003. The developmental role of serotonin: news from mouse molecular genetics. Nat. Rev. Neurosci. 4 (12), 1002-1012, Review.

Galuske, R.A., Schlote, W., Bratzke, H., Singer, W., 2000. Interhemispheric asymmetries of the modular structure in human temporal cortex. Science 289, 1946-1949.

Gharib, A., Balende, C., Sarda, N., Weissmann, D., Plenevaux, A., Luxen, A., Bobillier, P., Pujol, J.-F., 1999. Biochemical and autoradiographic measurements of brain serotonin synthesis rate in the freely moving rat: a reexaminations of the $\alpha$-methyl-L-tryptophan method. J. Neurochem. 72, 2593-2600.

Haber, R., Bessette, D., Hulihan-Giblin, B., Durcan, M.J., Goldman, D., 1993. Identification of tryptophan 2,3-dioxygenase RNA in rodent brain. J. Neurochem. 60, 1159-1162.

Herbert, M.R., Harris, G.J., Adrien, K.T., Ziegler, D.A., Makris, N., Kennedy, D.N., Lange, N.T., Chabris, C.F., Bakardjiev, A., Hodgson, J., Takeoka, M., Tager-Flusberg, H., Caviness, V.S., 2002. Abnormal asymmetry in language association cortex in autism. Ann. Neurol. 52, 589-596.

Hery, F., Chouvet, G., Kan, J.P., Pujol, J.F., Glowinski, J., 1977. Daily variations of various parameters of serotonin metabolism in the rat brain. II. Circadian variations in serum and cerebral tryptophan levels: lack of correlations with 5-HT turnover. Brain Res. 123, 137-145.

Hoshino, Y., Yamamoto, T., Kaneko, M., Tachibana, R., Watanabe, M., Ono, Y., Kumashiro, H., 1984. Blood serotonin and free tryptophan concentration in autistic children. Neuropsychobiology 11 (1), $22-27$. 
Hutsler, J.J., 2003. The specialized structure of human language cortex: pyramidal cell size asymmetries within auditory and language-associated regions of the temporal lobes. Brain Lang. 86, 226-242.

Hutsler, J., Galuske, R.A.W., 2003. Hemispheric asymmetries in cerebral cortical networks. Trends Neurosci. 26, 429-435.

Janusonis, S., Gluncic, V., Rakic, P., 2004. Early serotonergic projections to Cajal-Retzius cells: Relevance for cortical development. J. Neurosci. 24, 1652-1659.

Jones, M.B., Palmour, R.M., Zwaigenbaum, L., Szatmari, P., 2004. Modifier effects in autism at the MAO-A and DBH loci. Am. J. Med. Genet. 126B (1), 58-65.

Kahne, D., Tudorica, A., Borella, A., Shapiro, L., Johnstone, F., Huang, W., Whitaker-Azmitia, P.M., 2002. Behavioral and magnetic resonance spectroscopic studies in the rat hyperserotonemic model of autism. Physiol. Behav. 75 (3), 403-410.

Leboyer, M., Philippe, A., Bouvard, M., Guilloud-Bataille, M., Bondoux, D., Tabuteau, F., Feingold, J., Mouren-Simeoni, M.C., Launay, J.M., 1999. Whole blood serotonin and plasma beta-endorphin in autistic probands and their first-degree relatives. Biol. Psychiatry 45 (2), 158163.

Lebrand, C., Cases, O., Adelbrecht, C., Doye, A., Alvarez, C., Mestikawy, S.E., Seif, I., Gaspar, P., 1996. Transient uptake and storage of serotonin in developing thalamic neurons. Neuron 17, 823-835.

Leventhal, B.L., Cook Jr., E.H., Morford, M., Ravitz, A., Freedman, D.X., 1990. Relationships of whole blood serotonin and plasma norepinephrine within families. J. Autism Dev. Disorders 20 (4), 499-511.

Lord, C., Rutter, M., Le Couteur, A., 1994. Autism Diagnostic InterviewRevised: a revised version of a diagnostic interview for caregivers of individuals with possible pervasive developmental disorders. J. Autism Dev. Disorders 24 (5), 659-685.

Mayberg, H.S., Robinson, R.G., Wong, D.F., Parikh, R., Bolduc, P., Starkstein, S.E., Price, T., Dannals, R.F., Links, J.M., Wilson, A.A., 1988. PET imaging of cortical S2 serotonin receptors after stroke: lateralized changes and relationship to depression. Am. J. Psychiatry 145 (8), 937-943.

Missala, K., Sourkes, TL, 1988. Functional cerebral activity of an analogue of serotonin formed in situ. Neurochem. Int. 12, 209-214.

Muller, R.A., Rothermel, R.D., Behen, M.E., Muzik, O., Chakraborty, P.K., Chugani, H.T., 1999. Language organization in patients with early and late left-hemisphere lesion: a PET study. Neuropsychologia 37 (5), $545-557$.

Munn, D.H., Zhou, M., Attwood, J.T., Bondarev, I., Conway, S.J., Marshall, B., Brown, C., Mellor, A.L., 1998. Inhibition of T cell proleiferation by macrophage tryptophan catabolism. Science 281, 1191-1193.

Muzik, O., Behrendt, D.B., Mangner, T.J., Chugani, H.T., 1994. Design of a pediatric protocol for quantitative brain FDG studies with PET not requiring invasive blood sampling. J. Nucl. Med. 35, 104 (Abstract).

Muzik, O., Chugani, D.C., Chakraborty, P., Mangner, T., Chugani, H.T., 1997. Analysis of [C-11]alpha-methyl-tryptophan kinetics for the estimation of serotonin synthesis rate in vivo. J. Cereb. Blood Flow Met. 17 (6), 659-669.

Muzik, O., Chugani, D.C., Shen, C., da Silva, E.A., Shah, J., Shah, A., Canady, A., Watson, C., Chugani, H.T., 1998. Objective method for localization of cortical asymmetries using positron emission tomography to aid surgical resection of epileptic foci. Comput. Aided Surg. 3 (2), 74-82.

Muzik, O., Da Silva, E.A., Juhasz, C., Chugani, D.C., Shah, J., Nagy, F., Canady, A., von Stockhausen, H.M., Herholz, K., Gates, J., Frost, M., Ritter, F., Watson, C., Chugani, H.T., 2000. Intracranial EEG versus flumazenil and glucose PET in children with extratemporal lobe epilepsy. Neurology 54 (1), 171-179.

Nabi, R., Serajee, F.J., Chugani, D.C., Zhong, H., Huq, A.H., 2004. Association of tryptophan 2,3 dioxygenase gene polymorphism with autism. Am. J. Med. Genet. 125B (1), 63-68.

Osterheld-Haas, M.C., Vander Loos, H., Hornung, J.P., 1994. Monoaminergic afferents to cortex modulate structural plasticity in the barrelfield of the mouse. Brain Res. Dev. Brain Res. 77 (2), 189-202.
Patlak, C.S., Blasberg, R.G., Fenstermacher, J.D., 1983. Graphical evaluation of blood-to-brain transfer constants from multiple-time uptake data. J. Cereb. Blood Flow Metab. 3, 1-7.

Perry, A., Factor, D.C., 1989. Psychometric validity and clinical usefulness of the Vineland Adaptive Behavior Scales and the AAMD Adaptive Behavior Scale for an autistic sample. J. Autism Dev. Disorder 19, 4155.

Persico, A.M., Militerni, R., Bravaccio, C., Schneider, C., Melmed, R., Conciatori, M., Damiani, V., Baldi, A., Keller, F., 2000. Lack of association between serotonin transporter gene promoter variants and autistic disorder in two ethnically distinct samples. Am. J. Med. Genet. 96 (1), 123-127.

Persico, A.M., Pascucci, T., Puglisi-Allegra, S., Militerni, R., Bravaccio, C., Schneider, C., Melmed, R., Trillo, S., Montecchi, F., Palermo, M., Rabinowitz, D., Reichelt, K.L., Conciatori, M., Marino, R., Keller, F., 2002. Serotonin transporter gene promoter variants do not explain the hyperserotoninemia in autistic children. Mol. Psychiatry 7 (7), 795800.

Persico, A.M., Baldi, A., Dell'Acqua, M.L., Moessner, R., Murphy, D.L., Lesch, K.P., Keller, F., 2003. Reduced programmed cell death in brains of serotonin transporter knockout mice. Neuroreport 14 (3), 341-344.

Pietrzyk, U., Herholz, K., Heiss, W.D., 1990. Three-dimensional alignment of functional and morphologicaltomograms. J. Comput. Assist. Tomogr. 14 (1), 51-59.

Pietrzyk, U., Herholz, K., Fink, G., Jacobs, A., Mielke, R., Slansky, I., Wurker, M., Heiss, W.D., 1994. An interactive technique for threedimensional image registration: validation for PET, SPECT, MRI and CT brain studies. J. Nucl. Med. 35 (12), 2011-2018.

Piven, J., Palmer, P., 1999. Psychiatric disorder and the broad autism phenotype: evidence from a family study of multiple-incidence autism families. Am. J. Psychiatry 56 (4), 557-563.

Rasmussen, T., Milner, B., 1977. The role of early left-brain injury in determining lateralization of cerebral speech functions. Ann. NY Acad. Sci. 299, 355-369.

Salichon, N., Gaspar, P., Upton, A.L., Picaud, S., Hanoun, N., Hamon, M., De Maeyer, E., Murphy, D.L., Mossner, R., Lesch, K.P., Hen, R., Seif, I., 2001. Excessive activation of serotonin (5-HT) 1B receptors disrupts the formation of sensory maps in monoamine oxidase a and 5-ht transporter knock-out mice. J. Neurosci. 21 (3), 884-896.

Schain, R.J., Freedman, D.X., 1961. Studies on 5-hydroxyindole metabolism in autistic and other mentally retarded children. J. Pediatr. 58, 315320.

Seldon, H.L., 1981a. Structure of human auditor cortex. I. Cytoarchitectonics and dendritic distributions. Brain Res. 277-294.

Seldon, H.L., 1981b. Structure of human auditory cortex. II. Axon distributions and morphological correlates of speech perception.. Brain Res. 229, 295-310.

Seldon, H.L., 1982. Structure of human auditory cortex. III. Statistical analysis of dendritic trees. Brain Res. 249, 211-221.

Saito, K., Nowak Jr., T.S., Suyama, K., Quearry, B.J., Saito, M., Crowley, J.S., Markey, S.P., Heyes, M.P., 1993. Kynurenine pathway enzymes in brain: Responses to ischemic brain injury versus systemic immune activation. J. Neurochem. 61, 2061-2070.

Shoaf, S.E., Carson, R., Hommer, D., Williams, W., Higley, J.D., Schmall, B., Herscovitch, P., Eckelman, W., Linnoila, M., 1998. Brain serotonin synthesis rates in rhesus monkeys determined by $\left[{ }^{11} \mathrm{C}\right] \alpha$-methyl-Ltryptophan and positron emission tomography compared to CSF 5hydroxyindole-3-acetic acid concentrations. Neuropsychopharmacology $19,345-353$.

Shoaf, S.E., Carson, R., Hommer, D., Williams, W., Higley, J.D., Schmall, B., Herscovitch, P., Eckelman, W., Linnoila, M., 2000. The suitability of $\left[{ }^{11} \mathrm{C}\right]-\alpha$-methyl-L-tryptophan as a tracer for serotonin synthesis: Studies with dual administration of $\left[{ }^{11} \mathrm{C}\right]$ and $\left[{ }^{14} \mathrm{C}\right]$ labeled tracer. J. Cereb. Blood Flow Metab. 20, 244-252.

Sparrow, S.S., Balla, D.A., Cicchetti, D.V., 1984. The Vineland Adaptive Behavior Scales Manual. Circle Pines, MN: American Guidance Services. 
Stokking, R., Zuiderveld, H., Hulshoff-Pol, H., Viergever, M., 1994. intergrated visualization in biomedical computing. SPIE Press, Bellingham, WA.

Stout, D.B., Huang, S.C., Melega, W.P., Raleigh, M.J., Phelps, M.E., Barrio, J.R., 1998. Effects of large neutral amino acid concentrations on 6-[F18]Fluoro-L-DOPA kinetics. J. Cereb. Blood Flow Metab. 18 (1), 4351.

Suhonen-Polvi, H., Ruotsalainen, U., Kinnala, A., Bergman, J., Haaparanta, M., Teras, M.M., akela, P., Solin, O., Wegelius, U., 1995. FDG-PET in early infancy: simplified quantification methods to measure cerebral glucose utilization. J. Nucl. Med. 36 (7), 1249-1254.

Suzuki, S., Tone, S., Takikawa, O., Kubo, T., Kohno, I., Minatogawa, Y., 2001. Expression of indoleamine 2,3-dioxygenase and tryptophan 2,3dioxygenase in early concepti. Biochem. J. 355, 425-429.

Tohyama, Y., Takahashi, S., Merid, M.F., Watanabe, A., Diksic, M., 2002. The inhibition of tryptophan hydroxylase, and not protein synthesis, reduces the brain trapping of $\alpha$-methyl-L-tryptophan: An autoradiographic study. Neurochem. Int. 40, 603-610.

Von Stockhausen, H., Pietrzyk, U., Herholz, K., 1998. "3D-Tool”-A software for visualization and analysis of coregistered multimodality volume datasets of individual subjects. Neuroimage 7, S799.

Whitaker-Azmitia, P.M., 2001. Serotonin and brain development: role in human developmental diseases. Brain Res. Bull. 56 (5), 479485.

Wolf, W.A., Kuhn, D.M., 1986. Uptake and release of tryptophan and serotonin: an HPLC method to study the flux of endogenous 5-hydroxyindoles through synaptosomes. J. Neurochem. 46 (1), 61-67.

Yamazaki, F., Kuroiwa, T., Takikawa, O., Kido R, 1985. Human indoleamine 2,3-dioxygenase. Biochem. J. 230, 635-638.

Yan, W., Wilson, C.C., Haring, J.H., 1997. Effects of neonatal serotonin depletion on the development of rat dentate granule cells. Dev. Brain Res. 98, 177-184. 